\title{
Teleteaching with large groups: A case study from the Monash experience
}

\author{
Judith Tennant \\ Monash University
}

Teleteaching, though in a relatively early stage at Monash University, has the potential to provide a conduit for high level interaction between students and staff on various campuses in 'real time'. Whilst the technology holds valuable potential, there are unresolved discrepancies between 'what can be done' and the academics' understandings and common practice of 'what is actually being done' with teleteaching. It is only through research into current practices and attitudes that an understanding will be gained of the strategies that need to be adopted to ensure that teleteaching becomes an enriching learning experience for staff and students alike.

This article focuses on the perceptions and practices of staff within the realm of current training and support. It aims to provide an understanding of difficulties experienced in the use of teleteaching, and to suggest solutions emerging from the research. To illustrate current practices and attitudes towards the use of teleteaching, this paper reports on a study conducted by Tennant (1997) into the use of teleteaching at Monash University to deliver lectures between two campuses. The paper concentrates on androgogical, interaction and training issues in teleteaching with large groups of students as seen through the eyes of both academic staff and students.

\section{Background to the research}

At Monash, and probably at other tertiary institutions, teleteaching is impacting on a number of different aspects of teaching and learning, including teaching styles and student attitudes to learning, as well as administrative efficiency and operations.

The Monash strategic development document, (Leading the Way - The Monash Plan 1998-2002), describes Monash's aim of developing flexible teaching and learning environments. According to the Plan courses should be delivered "in new and flexible ways, ... [taking] advantage of the best current techniques and technology" (Monash University, 1997a p.6). Teleteaching is 
one of the 'new and flexible' ways being developed by Monash University to deliver courses.

Monash University is made up of six campuses - Berwick, Caulfield, Clayton, Gippsland, Parkville and Peninsula in the metropolitan and Victorian country area, with further campuses located in Malaysia and with a partnership presence in Hong Kong and Singapore. The diversity of teaching modes used by Monash University includes "academics teaching in conventional classrooms, electronic hook-up across campuses (teleteaching), open learning and distance education" (Monash University, 1997b, p.1).

The introduction of videoconferencing to Monash University came about through Department of Employment Education and Training (DEET) funding in 1991.Since this time the videoconferencing system has been extended and substantially modified to allow the introduction of teleteaching. In this respect, teleteaching is a modification of the videoconferencing system and refers to live two-way audio and video communication with the addition of 'enhanced tools' such as two-way computer and document camera linkages (Clarke, 1997). Teleteaching between the Berwick and Gippsland campuses of the University. became operational in April 1996.

Teleteaching provides many challenges for staff. As more and more staff are required to make use of the technology, it would seem reasonable to suggest that it is essential for them to gain an understanding of both the opportunities for teaching and learning that teleteaching provides, as well the problems pertaining to its use.

The aim of this study thus was to investigate how teleteaching was being used as a teaching tool, with a view to providing information and guidance, which might improve teaching and learning associated with it. Subjects taught from the School of Business and Electronic Commerce, within the Faculty of Business and Economics, were involved in these early trials and formed the focal point of the research.

A key factor in the decision by the Faculty of Business and Economics to introduce teleteaching, was the establishment of a campus at Berwick, designed to be a 'virtual' campus making extensive use of technology with minimal academic staff positioning. Teleteaching facilities were established on both the Berwick and Gippsland campuses. The School of Business and Electronic Commerce, Gippsland Campus, was responsible for running a number of courses at the Berwick campus and the staff are expected to make use of these facilities to reduce duplication of lectures 
and minimise travel between campuses ( $234 \mathrm{~km}$ round trip). Hence it would appear that economic and student load factors drove the introduction of teleteaching between the two campuses. Teleteaching was introduced and used to deliver lectures in the commencement of semester two 1996.

In this research the use of teleteaching as a teaching tool was approached from the perspectives of academic staff, students and technical staff.

\section{From the literature}

Whilst some previous work has been undertaken with regard to teleteaching, research on the educational application of large scale teleteaching is minimal, particularly as it may influence or operate within the environment of Monash University. In terms of existing research, almost all of the Australian literature on video conferencing focuses on small group interaction. The 'International experience' has also been examined, but the focus of this paper is primarily on the 'Australian' experience. For example trials conducted by the South Australian Department of Technical and Further Education (Schiller and Mitchell, 1993), Curtin University (Treagust, Waldrip and Horley, 1993) and La Trobe University (Goddard, 1995), all involved small numbers of students. The only case which used teleteaching to deliver lectures between large groups of students (250 students at one site, and 80 at a second site) was the 1995 trial by the University of Technology, Sydney (Freeman, 1996). This trial closely resembles the way in which teleteaching is being used at Monash University.

The literature does suggest a number of aspects of teaching and learning that need to be researched further with regard to teleteaching. As an example, the literature suggests that the use of teleteaching invites a change in androgogy. Schiller and Mitchell (1993), Ostendorf (1995), MacKinnon et al (1995), and Daunt (1997), all discuss the necessity of adopting a different teaching methodology than that used in traditional face to face lecture situations. For example, Schiller and Mitchell in evaluating SE DTAFE trials, state that video conferencing "requires a different teaching methodology from any that lecturers have previously used." (p.50). Teleteaching thus may involve placing a greater focus on 'human aspects' of teaching and learning, adopting a more learner centred approach to teaching, as well as becoming technically proficient at using the teleteaching facilities. 
Although referring specifically to interactive television, MacKinnon et al (1995, p. 91) states that "the nature of interactive television technology invites educators to [adopt] discussion based teaching, self-directed learning, ..... students must be actively involved in the learning process. ... We have found the most effective uses of interactive television to be those designed to sustain the interaction of participants in dialogue". These comments apply equally to teleteaching.

The benefits to student learning from interaction in a two-site learning environment have also been demonstrated in the literature (for example MacKinnon et al, 1995, Mason, 1994, Ostendorf, 1995). Providing students with the opportunity to interact not only with the lecturer in two way communication, but also with other students, enhances student learning. "Interaction has been shown to benefit learners at the affective level. It increases motivation and interest in the subject ...." (Mason, 1994, p.26)

It is claimed that teleteaching, using two way audio and two way video, has the potential to be as interactive as a face to face situation. However in this study, students interviewed, especially at the 'source' site, regarded teleteaching as no different to a normal lecture. They felt that the degree of interactivity largely depended on the personal style of individual lecturers, within the constraints imposed by unfamiliarity/glitches with the technology.

Freeman (1996, p.199) argues that there are preconceptions on the part of students and staff that lectures are "more a one-way interaction of presenter enlightening or entertaining the audience". Studies conducted by Mason (1994) support this view. Mason argues that students do not always rate interactivity in lecture situations as "highly as often assumed. ....[some] students find interactivity a waste of teaching time." (p.27). As will be noted later, the findings of this study with regard to questioning support this argument.

Mason (1994, p.30) observes that "Video conferencing tends to be used in situations which replicate face-to-face lecturing - not a teaching method known for deep level interactivity", while Brenzel (1995) is more scathing. He comments that if traditional face to face teaching is transferred to video conferencing "the marvellous 'interaction' component we have preserved for all this trouble is the same occasional question, except that we now need a series of monitors and expensive [equipment] to enable a student to ask it" (J11-J12). Elements of this view can also be found in the results of this study. 
Mason (1994) and Harris and Hague (1991) amongst others, argue that interaction is more successfully integrated into teaching where there are small numbers of students involved. The large group nature of teleteaching in this study questions the success of interaction.

Schiller and Mitchell (1993) emphasised the need for staff to be taught how to actually use the teleteaching system. They found that staff involved in the SE DTAFE trials felt that "the concerns about videoconferencing were so great as to restrict interest in the wider implications of its use.... [staff] felt the need to learn the basics of the operation" (p.48).These sentiments are reiterated by Baron and Orwig (1995). The findings of this study also highlight the need for training for both staff and students.

Treagust et al (1993), in evaluating videoconferencing as used by Curtin University found that students expressed dissatisfaction with lecturers being responsible for the technical operation of the videoconference. It distracted lecturers from their responsibility of teaching. Students indicated that they found lecturers need to focus more on the class itself and "not be distracted by the use of the technology." (p.324) Students interviewed from both the Gippsland and Berwick campuses also expressed the opinion that technical staff involvement is necessary with one student commenting: "I personally get annoyed that it is the lecturers that have to deal with [problems], I think there should be someone who sets the technology up."

In summary the literature suggests that aspects such as androgogy (adult teaching/learning methodology), the nature and techniques of interaction and the questions of appropriate training would seem to be concerns that need further research investigation. This project encompassed an exploration of these concerns within an existing operational framework.

\section{Research methodology}

The methodology used in the research project was that of a Case Study approach. A qualitative approach to the research was adopted as it was more appropriate to understanding the perceptions and deeper thinking of how staff and students really felt about the use of teleteaching.

Three main groups participated in the study. These groups were: 
- academic staff using teleteaching to deliver lectures,

- students participating in lectures taught via teleteaching

- technical staff providing support to academic staff using teleteaching.

Four lecturers who used teleteaching were interviewed. Nine students at both the Berwick and Gippsland campuses participated in the study. Two technical staff also participated in the study. Individual interviews were conducted to provide insight into the perceptions of participants, the problems that were encountered over the course of a subject, and the strategies adopted to overcome/minimise these problems. At the time of interview, each lecturer had only one semesters experience of using teleteaching. For students it was a first time experience, and whilst one technician had substantial experience, the other was relatively new to the area of teleteaching.

Each lecturer was asked a series of questions relating to their use of, and attitude towards, teleteaching. The questions were designed to explore whether or not the teaching methods currently adopted by lecturers were appropriate in the teleteaching environment. The questions were also designed to elicit information concerning lecturers' perceptions of the extent of instructional and technical support, both offered and required, for teleteaching to be used effectively.

Students from both Berwick and Gippsland campuses participating in the study were interviewed to determine their perceptions of, and their response to the use of teleteaching. Four students from the Berwick campus and five from the Gippsland campus were interviewed. Each student was asked the same series of questions. These questions were designed to determine student expectations of a lecture and whether or not lectures delivered via teleteaching met these expectations. In cases where there was a divergence in expectations, it was important to discover the reasons for the divergence. Questions asked incorporated the following areas:

- prior knowledge/expectations concerning teleteaching

- future preferences for learning

- operational issues - site location/preferences, physical comfort with teleteaching

- desired level of interaction

One technical support staff member from each of the Berwick and Gippsland campuses was interviewed to determine their perceptions of the nature of support available to staff, in terms of training and on-going 
support, and the ways in which staff could improve their presentation from a technical viewpoint. These support staff provided technical assistance to academic staff as required during the running of a teletaught lecture. They were also heavily involved with the running of training sessions for teleteaching.

Technical staff were asked a series of questions which aimed to provide the research with a better understanding of the technical operation of the teleteaching facilities. Both technology potential and technology limitations were explored. Questions also sought insight into the nature of technical training currently being offered and ways in which this training could be improved. Questions to technical staff addressed the following key areas:

- nature of the teleteaching facilities

- operational features of the system

- involvement in training

- perception of major problems faced by academic staff in using teleteaching

- proposed changes to the system.

In order to establish a more holistic perspective for the study, information and data from a number of additional sources were used. Training sessions conducted by the Centre for Higher Education Development, (an internal professional development group at Monash University), were attended to determine the nature and extent of training received by lecturers using teleteaching. A workshop conducted by an external consultant was also attended to gain a further appreciation of the way in which teleteaching was used in other areas. Although very useful, the consultant's experience centred on the use of teleteaching in small group situations. A number of teleteaching sessions delivered from both the Gippsland and Berwick campuses were attended to observe teaching styles adopted by various staff. This also allowed observation of both student and staff reactions to the teleteaching environment.

\section{Results and discussion}

The three areas identified by this research which suggest a need for urgent consideration by those anticipating adopting a teleteaching approach are: androgogical issues including the roles of academic and technical staff; the nature of and extent to which interaction should be incorporated into teleteaching situations, professional development for staff and students. 
All aspects are interconnected, but for the purposes of this discussion are dealt with individually.

\section{Androgogical issues}

One perception which arose from this study, and which may appear elsewhere, relates to the difficulties experienced in delineating the role of teacher from the role of technician in the use of teleteaching. This will become a matter of increasing importance needing clarification as the use of teleteaching becomes more widespread.

As noted by Clarke (1997), the teleteaching facilities were designed with the intention that the lecturer would require no technical support to operate the various functions available. This mirrors the organisation of systems used in other universities (Grant, 1992 and Schiller and Mitchell, 1993). Academic staff interviewed expressed the view that the academic's role is to 'teach', not to operate technical equipment. Although some staff are happy to operate independently of technical staff as much as possible, others feel that the operation of any technical equipment - especially making the connection between sites - is strictly a task for technical staff.

With regard to aspects of presentation, lecturing staff experienced a degree of difficulty and discomfort in terms of striking a balance of 'eye contact' with each site during the lecture. The necessity of looking at the camera in an attempt to 'engage' the remote site, often meant that 'contact' was lost with the source site. Presentation techniques become an important aspect of an androgogical approach in teleteaching.

A further inhibiting factor resulted from the physical restriction of the lecturer behind the lectern. A work space of approximately 3 metres is available for staff to move around without going out of 'camera shot'. Included in this work space are the PC desk, the lectern and the document camera desk (Clarke, 1997, p. 7).

Teaching is further restricted, in that movements by the lecturer must be relatively slow to avoid transmission of a 'jerky' image to the remote site. As a result, lecturers found themselves having to adjust to confining themselves to a small space, avoiding excessive hand/body movements. They considered body language an important part of communication. Without it, lecturers had to learn to use and recognise non-verbal cues to interact with students. 
The positioning of microphones in the lecture theatres actively discouraged interaction. Questioning and encouraging dialogue are very hard to achieve in the current teleteaching environment at the Berwick and Gippsland campuses. Student interviews indicated a strong aversion on the part of students to participate in question/answer sessions. This was largely due to the need for students to: leave their seat; walk to a microphone; activate the microphone; and then have a camera zoom in on them to display their image at the 'other' site.

One further problem facing lecturers is that of the lack of technical proficiency. A major problem faced by academics, and identified in this study was the need to become technically proficient in using the teleteaching facilities. Although excellent technical support was provided, the system was designed to be self sufficient and lecturers are encouraged to operate the various technical functions themselves. This creates a problem for academics trying to balance concentration between the 'equipment' and the delivery of 'course content'. Students expressed feelings of frustration at the amount of time wasted due to delays and advocated staff either become more proficient or have a technical person present to ensure the smooth running of the facilities. "There needs to be more support, so that glitches don't hold up the process"(Student Interviews).

Staff found that they had to spend time becoming technically proficient at using the teleteaching equipment and believed they required considerably more training and practice until they would become comfortable in the teleteaching environment. Teaching via teleteaching also required staff to spend time 'rehearsing' to ensure that activities planned for any given lecture were 'possible' in terms of technical requirements.

Students expressed a number of concerns in being located at the remote site of a teletaught lecture. Of main concern was the feeling of not being a part of the lecture. "I may as well sit at home in front of the TV" and "it took away the human factor"(Student interviews). They also experienced problems in terms of an inability to seek help during breaks in a lecture or at the end of the lecture. Even though communication via the microphones was possible, this was not regarded as a desirable option.

Suggested strategies by the findings to counteract this 'dehumanising' of the lecture focus mainly on providing increased opportunities for student contact. By varying the delivery site, students/ lecturers have the 
opportunity of developing a personal relationship. This makes 'remote' students feel a more integrated part of the class. Students interviewed all expressed a strong preference for alternating delivery sites, rather than being continually located at the remote site.

The notion of teaching and learning strategies is interwoven with the concepts of interaction.

\section{Interaction}

As Burke et al (1996) highlight, interactivity is not an attribute of the medium, but something which must be actively incorporated into its use. Interactivity is a very complex concept and the findings of this study indicated a number of dimensions.

Interviews with academic staff indicated a need for staff members to be located at the remote site for 'crowd control' purposes. The findings suggest that these staff members could better be used to aid in a number of interactive activities during the lecture, rather than simply performing a 'baby sitting' role. They would then provide an additional point of contact for students and theoretically increase the potential for interactivity.

A further avenue of providing interactivity might be through increased personal contact between staff and students outside of lecture times. This can be achieved by providing increased channels of communication via the telephone, email etc, so that students at the remote site have a similar level of access to staff as do students at the source site. As Freeman (1996) noted, this study also found that students at the remote site found reduced access to the lecturer a serious problem.

With regard to interaction, students generally found they had a reduced concentration span when they were located at the remote site. This was attributed to both difficulties in focusing on the 'screen' images of either the lecturer or computer program being transmitted, as well as to disruptions from fellow students. The former was generally the more significant factor.

As Mason (1994) and Brenzel (1995) have indicated previously, the level of interaction in traditional face to face lectures is not necessarily very high. Academic staff and student interviews indicated a common view that "students are basically sitting there to get the notes, [in a telelecture]. 
There is not a huge amount of interaction in the lecture regardless of whether it's by teleteaching or whether it's just an internal lecture."

Academic staff interviewed reported great difficulty in eliciting responses from students. This problem was also identified by Freeman (1996), in the University of Technology trials. He found that "attempts to have staffstudent interactions, a critical component for student learning, also took longer than normal. This was particularly the case for students at the remote campus..." (p.203)

Further, this study indicated that students at both sites were resistant to being included in interactive activities such as question and answer sessions. They felt embarrassed having to use the microphones to communicate with the other site. This was due to difficulties in accessing microphones in an inconspicuous fashion, and the fact that they could not see the entire audience they were addressing. The view that the lecturer "is just there to give us information" was commonly expressed.

If an androgogical shift involving a higher level of interaction is deemed desirable, (discussed further below) then it is apparent that the attitudes and expectations of both students and academic staff may need to be altered.

\section{Professional development}

A clear message from both academic staff and technical staff interviewed was that training in the use of the teleteaching facilities needs improvement. Both groups expressed concerns over the lack of 'hands on' training provided. As noted earlier, students expressed dissatisfaction with the level of technical competence of staff in using teleteaching equipment.

It was reported that even where time for 'hands on' training was provided within training sessions, many academic staff were reluctant to 'take over' the controls. Some academic staff feel intimidated by the teleteaching system. The question of intimidation is not easy to address but appears to have two aspects. Firstly there is the extent to which staff feel intimidated by the technology itself. What for some staff members appears intriguing, to others really is quite frightening. Not all are equally comfortable with technology and the degree of expertise of staff who may be called upon to use teleteaching is not a constant. 
Secondly, intimidation occurs in the sense that staff are being asked to combine a reasonably complicated technical system with a lecturing situation which, on its own, can be quite stressful for the individual concerned.

Academics noted the feature of information overload. As Schiller and Mitchell (1993, p. 55-56) point out, avoid showing newcomers "all the variations and even the pitfalls of videoconferencing ... [remember] the neophyte users needs are quite basic as they focus on 'survival' strategies in initial use." This was the case for some of the participants in the study.

From the findings, both Academic and Technical staff would like to see training as an ongoing process, with sessions prior to the start of each semester as well as a session a few weeks into the semester. Participants in the study believe that this would also allow staff time to identify problems which seem to occur consistently.

Staff interviews indicated the importance of networking with others. Networking and mentoring on an informal basis, was one of the mechanisms used by staff to cope with the many challenges teleteaching presented. It allows academic staff to share problems and possible solutions in a non-threatening environment. Ostendorf (1995) suggests that staff will become more proficient with the technology if ideas and techniques are shared by all using the technology.

Students also noted the need for technical awareness. The study found that students would prefer to be given an explanation of how teleteaching operates and the way in which it was going to be used by individual lecturers at the beginning of the semester.

\section{Conclusions and future directions}

Monash is one of a number of institutions where teleteaching has been introduced. Lessons learned from this study may be applicable to other institutions who have either adopted teleteaching or who are moving in this direction. The successful adoption of teleteaching provides challenges for professional development groups, academic staff and students. This paper aimed to highlight key issues involved in the use of teleteaching as a teaching tool. 
Three main issues stand out as being of major importance if teleteaching is to be used effectively as a teaching tool. These relate to androgogical issues, interaction and training. All three are inter-related and require further research.

It was apparent from the study that teleteaching was imposed upon academic staff for what were regarded as largely economic reasons. If staff and students are to embrace teleteaching, then they must first be convinced that there are some benefits, other than economic, of using teleteaching. This may require bringing about a change in the way students and academic staff think about both lectures and tutorials and perhaps even more fundamentally the nature of teaching and learning. That is, an androgogical shift in attitudes may be required. In order to achieve this, more research needs to be done into the nature of interaction appropriate in a variety of teaching situations, one of which is teleteaching. This is a critical issue which need to be examined in more extended research. Training, which is ongoing in nature, should be provided to allow for the integration of an interactive learning environment for both students and staff. The nature of interaction applicable must be considered within the context of individual learning situations.

Research needs to be expanded using a more extensive data base, to further examine the nature of interaction and strategies for dealing with large group situations. Evaluations need to be made of the role of traditional lecturing methodology within a complex technological environment. In addition further research is needed into determining whether or not teleteaching does in fact have benefits (other than economic) for students and/or academic staff, within the context in which teleteaching is currently being used at Monash University. The methodology of teaching approaches in alternative environments provides a vista of research avenues. Whatever the research strand adopted, the focus of research needs to be directed towards the human aspects of teleteaching, if teleteaching is to become an accepted teaching tool reaching its full potential.

\section{References}

Baron, A. E. and Orwig, G. W. (1995). Multimedia Technologies for Training: An Introduction, Libraries Unlimited, Inc, Englewood, Colorado.

Brenzel, J. (1995). The False Premise in Teleteaching. Ed, Education at a Distance, V.9. N.4, ppJ11-J12. 
Burke, C., Daunt, C., and Lundin, R. (1996). “Videoconferencing in an Med Program: A Case Study in Flexibility and Empowerment", in Proceedings of Open Learning '96, Queensland Open Learning Network. Brisbane, pp1-6.

Clarke, N. (1997). Teleteaching Facilities at Monash University: An Introductory Guide for Users, Monash Computer Centre. Clayton.

Daunt, C. (1997). Introducing and Implementing a New Technology, paper presented at Telecom Europe Helsinki, 16-18 June.

Freeman, M. (1996). Video Conferenced Mass Lectures. Proceedings of ATA Tele Con '96, ATA, Brisbane, pp195-209.

Goddard, J. (1995), Perspectives on Videoconferencing. In Pearce, J.M., and Ellis, A., (eds), Learning with Technology, ASCILITE '95 Conference Proceedings, 4-6th Dec., Science and Multimedia Teaching Unit, University of Melbourne, pp205214

Grant, M. (1992). Ecunet: Edith Cowan University's Video Conferencing Network: Two Years On. In Hedburg, J.G., and Steele, J., (Eds), Educational Technology for a Clever Country: Selected Papers from EdTech '92, University of Adelaide, Sth Australia, pp1-9.

Grant, M. (1992). Videoconferencing Utilising a Full Band Width Mode of Delivery. In Herrington. J. (ed), Distance Education and Future Visions, Western Australian Distance Education Consortium, Murdoch, WA. pp39-50.

Harris, C., and Hague, M. (1991). Meeting at a Distance: How Video Conference Tutorials Enhance Teacher Learner Relationships. In Atkinson, R., McBeath, C., and Meacham, D. (eds), Quality in Distance Education: APESA Forum '91, pp193198.

MacKinnon, A., Walshe, B., Cummings, M. and Velonis, U. (1995). An Inventory of Pedagogical Considerations for Interactive Television. Journal of Distance Education, 10(1), 75-94

Mason, R. (1994). Using Communication Media in Open and Flexible Learning, Kogan Page, London.

Monash University (1997a). Leading The Way: The Monash Plan 1998-2002, Monash University, Clayton.

Monash University (1997b). Distance Education Handbook 1988, Monash University, Clayton.

Moore, M.G. (1989). Editorial: Three types of Interaction. The American Journal of Distance Education, Vol.3 No.2, pp1-6. 
Ostendorf, V. (1995). Distance Learning: Modern Solutions for Education Today, Virginia Ostendorf Inc, Littleton Colorado.

Schiller, J., and Mitchell, J. (1993). Interacting at a Distance: Staff and Student Perceptions of Teaching and Learning via videoconferencing. The Australian Journal of Educational Technology, 9(1), 41-58.

http: / / www.ascilite.org.au/ajet/ ajet9/schiller.html

Tennant, J.K. (1997). Exploration of Strategies/Techniques Using Teleteaching as a Teaching Tool, Master of Educational Studies Project, Monash University.

Treagust, D. F., Waldrip, B. G., and Horley, J. R. (1993). “Effectiveness of ISDN video-conferencing: A Case Study of Two Campuses and Two Different Courses", Distance Education, 14(2), 315-330.

Judith Tennant

Faculty of Business and Economics

Monash University

judith.tennant@buseco.monash.edu.au 